\title{
Effective bank regulation: seven guiding principles
}

Article

Accepted Version

Arch, L. (2020) Effective bank regulation: seven guiding principles. Journal of Financial Regulation and Compliance, 28 (2). pp. 301-314. ISSN 1358-1988 doi:

https://doi.org/10.1108/JFRC-06-2019-0075 Available at https://centaur.reading.ac.uk/89343/

It is advisable to refer to the publisher's version if you intend to cite from the work. See Guidance on citing.

To link to this article DOI: http://dx.doi.org/10.1108/JFRC-06-2019-0075

Publisher: Emerald

All outputs in CentAUR are protected by Intellectual Property Rights law, including copyright law. Copyright and IPR is retained by the creators or other copyright holders. Terms and conditions for use of this material are defined in the End User Agreement.

\section{www.reading.ac.uk/centaur}

\section{CentAUR}

Central Archive at the University of Reading

Reading's research outputs online 


\section{Structured Abstract}

\section{Purpose}

This article is a 'Viewpoint' article and as such, it presents the author's opinion and interpretation. Its primary purpose is to propose seven guiding principles for effective bank regulation so that these may be subject to academic criticism.

\section{Design/methodology/approach}

The principal theme of this article has its origins in archival research into the nature of bank regulation in the UK in twenty-five to thirty years after the Second World War. This article draws upon insights gained into the nature of bank regulation in the UK arising from that research. It focuses on what aspects of bank regulation were effective in that earlier period. It then attempts to convert those insights into underlying principles.

\section{Findings}

Seven principles are proposed as the starting point for a discussion as to the principles which should underpin effective bank regulation. The seven principles are set out in the Introduction to the article.

\section{Originality/value}

The framework for the regulation of banks in the UK and in many other countries is a complex one. The general trend in bank regulation in the UK in the last four decades has been technocratic, characterised by a preference for codified rules which are often detailed and technically complex. It has also been characterised by the establishment, or further development, of intricate regulatory and supervisory structures at national, international and supranational levels. Scholarly attention has understandably been focused on those trends. Rather less attention has been given to the broader principles which might underpin and guide bank regulation. This article seeks to contribute to that question. 


\section{Introduction}

For those interested in the development of the banking system in the UK over the last four decades, two trends are very remarkable. First, from the 1970s the banking system has become less stable, certainly in comparison with the twenty-five to thirty years after the Second World War - a period sometimes referred to as the 'Golden Age of Capitalism'. The period from 1945 until the early 1970s was a period of stability in banking in the UK (and in many other countries) and one in which there was a high degree of compliance with regulation. Taylor (2010, p. 371) observed that "the post-war period of financial repression (including capital controls but also strict regulation of domestic finance) was a remarkable era in combining rapid economic growth and high investment with a crisis-free but strictly regulated and supervised financial system in most countries. This is a remarkable historical fact that warrants further study." Reinhart and Rogoff (2009, p. 205) showed, based on their analysis of sixty-six countries, that the absence of banking crises from the 1940s until the early 1970s was a noticeable feature of many banking systems. Grossman (2016, Section 6) recently suggested that this period "constitutes the longest period of banking stability this industrialized world has ever known." During the 1970s, in contrast, the banking system became less stable as the postwar regulatory framework disintegrated or was dismantled, and in the UK in December 1973 a crisis of the secondary banks broke, part of a wave of bank failures in 1973 and 1974. Laeven and Valencia (June 2012, p. 3) put the number of banking crises globally in the period from 1970 to 2011 at 147, a period which encompasses the global financial crisis of 2007-09. Wolf (2004, p. 280) opined that "The age of financial liberalization has, in short, been an age of financial crises."

Second, bank regulation over the last four decades has been technocratic. It has been characterised by a preference for rules which are codified, and which tend to be detailed and technically-complex. It has also been characterised by the establishment, or further 
development, of intricate regulatory and supervisory structures at national, international and supranational levels. For UK banks, as well as UK legislation and EU regulations and directives, those banks which are internationally active comply with the Basel III framework developed under the aegis of the Basel Committee on Banking Supervision [1]. The very largest global banks - the global systemically important banks or 'G-SIBS' - are subject to additional regulatory requirements. A further aspect of the international framework is the Financial Stability Board, established by the Group of Twenty in 2009 as a successor to the Financial Stability Forum, with a mandate to coordinate at an international level the work of national financial authorities and international standard setting bodies. The framework for the regulation of banks in the UK and in many other countries is thus a complex one. This complex framework reflects and is in part a response to the fact that many banks and financial institutions have become more complex since the 1970s in terms of the products and services they sell, the global nature of their operations, and their corporate structures.

The theme addressed in this article has its origins in a research project into the nature of bank regulation in the UK in twenty-five to thirty years after the Second World War on the assumption that an understanding of that earlier period of bank regulation may be of some use to today's policymakers and regulators. Taylor (2010, p. 366) pointed out in the immediate aftermath of the global financial crisis that "if ever comparative economic history had a time when it could and should speak to issues of global importance, then that moment is surely now." This insight was echoed in the 2013 report of the UK's Parliamentary Commission on Banking Standards, "Changing Banking for Good" [2]. In a section titled 'Raising historical awareness' a number of witnesses set out the reasons why an historical perspective on financial crises might form a useful part of the training of professional regulators: 
We heard from Lord Turner and Martin Wheatley that ensuring supervisors learn the lessons of past financial crises has not formed part of the training programme for supervisory staff. Martin Wheatley told us that while the FSA [Financial Services Authority] had covered recent crises in its training, this only spanned the last five years: "We have built into our training certainly the lessons from the recent crisis the past five years. It is an interesting point as to whether we should take a more expansive view and look at the repeated crises over a longer time period, but certainly the past five years have been very much built been into our approach."

Lord Turner was in favour of increasing awareness amongst supervisors of historical events: "I will now encourage the PRA in particular to do that and to say, "Is there a history element of it?' You are quite right that there are a series of banking crises which have extraordinarily common features. Too much lending to commercial real estate which goes up in value, which then encourages more lending and, for a period of time, makes people feel that the risks have disappeared - is one of the most common features of everything from the Scandinavian crisis of the early 1990s to the Japanese, etc."

The regulators have not customarily ensured that their staff acquire awareness of previous financial crises, even though it is evident that there is repetition in the underlying causes. This is a serious omission. The PRA [...] should ensure that supervisors have a good understanding of the causes of past financial crises so that lessons can be learnt from them [3].

While "Changing Banking for Good" places emphasis on an historical understanding of financial crises, regulators may also benefit from understanding periods of stability in 
banking, particularly in terms of the regulatory arrangements that underpinned them, since understanding the regulatory framework in an earlier period may, it has been suggested (1992, p. 15), broaden regulators' thinking about "the range of possibilities at our disposal now."

The primary purpose of this article is not to explore the nature of bank regulation in that earlier period in detail. Its purpose, rather, is to set out seven guiding principles for effective bank regulation, as follows:

1. The basis of effective regulation is the legitimacy of the regulator(s) and of the regulations;

2. An effective regulatory framework depends upon the placing and accepting of trust. This in turn depends upon trustworthy banks and bank regulator(s);

3. There are limits to the effectiveness of codified, formal regulation;

4. The regulatory framework should promote simplicity and discourage complexity with respect to regulation and to the structure of regulated entities;

5. The regulatory framework should have a broad rather than a narrow conception of what drives individual behaviour within the regulatory process;

6. Regulation should encourage the development of excellence in banking, that is to say, the development of banking as a "practice";

7. The political and social objectives of regulation and competition must prevail over economic ones, if there is a conflict.

In the seven sections which follow, each principle is explained and explored in turn.

\section{Legitimacy}

The postwar period of bank regulation brings to the forefront the importance of legitimacy. The regulator and its regulations need to be regarded as legitimate by both the 
regulated entities themselves, and by the public, given that an important rationale for bank regulation is that it advances the public interest. The importance of the legitimacy of the lawmaker or regulator, according to Tyler $(2009$, p. 313,318$)$, is that it generates "the feeling of responsibility and obligation to follow the law, to accept the decisions of legal authorities, and to co-operate with and help legal authorities to do their jobs" arguing that "legitimacy has an influence upon behaviour that is equal to or greater than that of the risk of punishment." Legitimate orders are more likely to be stable because of their binding quality. Boulding (1969, p. 3-7) analysed how and why central banks gain legitimacy and concluded that there are six sources of a central bank's legitimacy [4]. Two are particularly important. The first is what Boulding (1969, p. 3) terms "payoffs." There must be positive and visible "payoffs" to society in exchange for the power which society vests in its central bank. Leslie O’Brien, governor of the Bank of England from 1966 until 1973, recalled how the Bank enhanced its status as a legitimate organization during and after the Second World War in part because it had administered the control of foreign exchange so efficiently [5]. The second source is "sacrifices" made by the regulated entity (such as when a bank complies with a regulation or request, even though such compliance may be to the detriment of its own interests). Such sacrifices signal the central bank's legitimacy. On the other hand, once an institution demands a great deal but gives very little in return its legitimacy will diminish Boulding (1969, p. 3) argues. Its demands begin to lose their binding quality. The high levels of compliance with regulation by the clearing banks in the postwar decades provide a strong indication that the Bank and its regulations were legitimate. The regulatory framework needs to develop, maintain and strengthen the legitimacy of the regulator and its regulations. The question to be asked about any proposed new regulatory policy is whether it strengthens or weakens the legitimacy of the regulator and its regulations. 


\section{Trust and trustworthiness}

There has been a quite dramatic change in the way in which banks in the UK are perceived by the public over the last thirty to forty years. In 2013, the British Social Attitudes Survey 30 reported on "perceptions of how well major institutions are run." In 1983, 90 per cent of those asked regarded the banks as being well run. By 1994, the figure had fallen to 63 per cent and by 2012 was a mere 19 per cent. This was "probably the most dramatic change of attitude registered in 30 years of British Social Attitudes"[6]. A plausible interpretation of this finding is that there has been a precipitous decline in the perceived trustworthiness of banks. A notable feature of the regulatory system in the earlier period, closely connected to legitimacy, was trust and trustworthiness. In 1964, BBC Two broadcast a television series "Men [sic] and Money: The City in the 1960s: A Portrait of the Bankers who Ran London's 'Square Mile"” The second episode, "A Question of Confidence," was subtitled "People Trust Banks and the Banks Trust the Government"[7]. Nooteboom (2014, p. 159-61) suggests that trust is linked to the concept of control because trust and control are both complements and substitutes. On a continuum, control and trust can exist together sharing the continuum, or control can replace trust, albeit never completely. Thus, the more one exerts control, the less one relies upon trust. The fact that the Bank of England relied upon forms of regulation extra-legal (or non-statutory) and self-regulation - that lie more towards the trust than the control end of the continuum was evidence of an assumption of trust. Although trustworthiness may seem too abstract a concept to be of use in day-to-day supervision and regulation this need not necessarily be the case, providing that trustworthiness can be operationalized. O'Neill for example, argues that being trustworthy means being honest, competent and reliable [8]. Nooteboom (2014, p. 159) sees trust as a "disposition" with respect to someone's competence and intentions. We place trust in another's competence 
(their "technical ability to act in line with agreements") and in their intentions - the "will and commitment" to act "according to the best of one's ability, and not to cheat." For Mayer et al. (July 1995, p. 717-20) a major proportion of trustworthiness is explained by the trustee's ability, their benevolence and their integrity. A trustworthy bank or banker is thus technically competent, has integrity and has benevolent intentions towards their customers. O'Neill (2014) argues that increasingly, regulation is seen as a substitute for trust; because an agent cannot be trusted, regulation is required. She suggests that, on the contrary, regulation should rest upon trust - it complements trust, as Nooteboom would see it. To see regulation as a substitute for trust leads to an infinite regress: the agent cannot be trusted and so needs to be regulated, the regulator of the agent cannot be trusted and therefore also needs to be regulated, and so on. This logic is evident in the emergence in the last several years in many countries of "fiscal watchdogs," such as the Office for Budget Responsibility (OBR) in the UK. The very existence of the OBR assumes that the existing apparatus for monitoring the public finances cannot be trusted [9]. In the context of contemporary banking, Nooteboom's insight, that in situations of high uncertainty or in situations where monitoring is difficult one necessarily becomes more reliant on trust, is salient. The regulatory framework needs therefore to persuade or incentivize banks to develop, maintain and strengthen their trustworthiness. As suggested by O'Neill, from a policy perspective this means that when the provision of information is used as a regulatory tool the information submitted to the regulator should provide (among other things) "adequate, useful and simple evidence" of that bank's trustworthiness [10].

\section{Codification}

Regulation today tends to be more formal and codified than in the earlier period. According to Casu et al. (2015, p. 205) this is a response to bank failures and financial 
innovation, as a result of which the "scope and complexity of financial regulation have tended to grow almost continually." Since the global financial crisis, the trend towards a style of regulation which is formal and codified, and focused on structures - evident since the 1970s - has continued, as has the preference for detailed rules. These rules have tended towards greater complexity reflecting the more complex nature of banks and the often global nature of their operations [11]. To give one example, Basel III requires adherence to a Liquidity Coverage Ratio "to promote the short-term resilience of the liquidity risk profile of banks"[12]. This one ratio alone takes 75 pages to explicate.

In the aftermath of the global financial crisis, the risks associated with the growing scope and complexity of regulation - and the concomitant codification of regulation - have been exposed, however. The central weakness of increasingly formal and codified regulation is that it encourages what McBarnet calls "legal engineering." The codification and formalization of regulation in the form of 'hard' law as a response to bank failures and crises, may however, have the unintended consequence of contributing to them. Legal engineering, McBarnet $(2010$, p. 72, 79) argues, was a causal factor in the recent crisis. She explains that "creative compliance thrives on rule-based regulation, for tight specific rules provide particularly solid material for legal engineers to work with," arguing that "whatever regulation is put in place, business - in this case banks - will routinely respond by seeking out ways to circumvent it." Counter-intuitively, codified regulation may be easier to circumvent than regulation in other forms. The self-regulatory, 8 per cent cash ratio adhered to by the London clearing banks purely by convention until 1971 was not possible to avoid because the cash ratio for each clearing bank was shared with the other London clearing banks as well as with the regulator through its inclusion on the "Monthly Statement of Balances of London Clearing Banks." 
In a similar vein, Marandola and Sinclair $(2014$, p. 6), following the philosopher John Searle, argue that as we rethink bank regulation a distinction should be drawn between “constitutive rules" and "regulative rules." Regulative rules (Searle, 2005, p. 9) "are typically in the form 'Do X'." A regulative rule might be to drive on the right-hand side of the road. In contrast, the rules of football are constitutive ones. They "not only regulate but rather constitute the very behaviour they regulate." Marandola and Sinclair $(2014$, p. 6) suggest that the focus since the crisis has been placed, incorrectly, upon rewriting "the regulative form of rules and on those who allegedly broke these" whereas it should have been placed upon rethinking those constitutive rules which were "damaged" in the crisis. For example, many banks now make loans under the "originate-to-distribute" model of bank lending (as opposed to the previous "originate-to-hold" model). A focus on regulative rules might seek to develop and codify detailed, technical rules better to regulate loans made under the "originate-todistribute" model. A focus on constitutive rules might lead one to question whether “originate-to-distribute" loans properly constitute banking.

The policy implication of this principle is that policymakers need to consider using regulation in all its forms. In addition to codified regulation, constraints may be imposed in non-statutory - or 'soft law' form and self-regulatory form. Policymakers should explore and test which form of regulation is most appropriate, given the specific policy objective.

\section{Simplicity}

Highly complex regulation may have unintended consequences for the banking system. First, it creates the risk of reduced competition, as complex regulation is a barrier to entry into banking, leading to a system dominated by banks that are deemed 'Too Big to Fail'. Only large banks with well-resourced compliance and legal functions are able to operate in a regulatory framework of highly complex rules. Second, highly complex 
regulation may be prone to regulatory capture in a way that is less likely with either simple regulation or regulation in other forms. This might arise from the superior technical knowledge of bank staff, as compared with the regulator. Third, the complexity of regulation may render it ineffective according to Slattery and Nellis (2011, p. 1) because "regulators have bounded rationality"[13]. Beck et al. (March 2016, p. 29), in their analysis of the regulatory response to the global financial crisis in Europe, identify as an unresolved problem the "ever-increasing complexity of the financial system" and recommend that complex regulation be "complement[ed] [...] with some simple rules." These consequences of growing complexity point to a third guiding principle: increasing the complexity of regulation is unlikely to prevent or reduce instability in the banking system and may even increase it.

In parallel with the increasingly complexity of regulation, individual financial institutions have themselves become structurally more complex, often reflecting an increase in the scope of their activities. Herring and Carmassi (April 2015: 4.1 Introduction) point out that since the global financial crisis it has not been possible to stop or reverse the trend towards complex financial institutions: "the overall degree of complexity (as measured by the number of subsidiaries) has not decreased since the crisis." Although a limitation of this research is that they judge complexity according to a single measure (the number of subsidiaries), there does seem to be an association between complexity, and size and scope. Thus, the problem of 'Too Big to Fail' banks has not been resolved. Another dimension of complexity is the transformation of clearing banks from specialist institutions - "boring banks" - into what Johnson and Kwak (2011, p. 85, 215) refer to as "financial juggernauts" or "financial 'supermarkets' that could provide the full range of financial services to both retail and corporate customers, anywhere." They argue that "all banks, including risk-seeking ones, should be limited to a size where they do not threaten the stability of the financial system." Based on a sample of European Union headquartered banks for the period 1992 to 
2007, De Jonghe (2010, p. 414) suggests that "the shift to non-traditional banking activities [...] reduces banking system stability." Watson $(2013$, p. 7) posits that a tendency towards complexity may be inherent not just to banking but to highly regulated industries generally. There may be, he suggests, "an endogenous tendency for industries to increase complexity as a means of dominating the regulatory debate or shutting others out." The important point for regulators suggest Herring and Carmassi (April 2015, p. 2) is that the existence of complex banks "is itself a significant source of systemic risk."

An insight into how regulators might think about the regulation of highly complex systems is offered by the law of requisite variety, derived from cybernetics. According to this law, in any regulatory process the variety in the regulator must be at least as great as the variety in the system being regulated. Umpleby (December 1989, p. 586) observes that in the face of complexity there is an almost natural tendency to respond with greater variety - or complexity - in the regulator:

whenever one is confronted with a situation more complex than one can cope with, there are only two ways to approach the problem - either increase the variety in the regulator $[\ldots]$ or reduce the variety in the system being regulated. The first impulse of people is usually to increase the variety in the regulator.

He argues that the second approach - that of reducing the variety in the system being regulated - may more effective. If financial institutions (and / or the financial system within which they operate) increase in variety, it may be difficult for the regulator to respond with greater variety by, for example, creating a new specialist regulator. It may simply not have the resources to do so. In this case, its only option would be to reduce the variety within the system being regulated. Reforms such as the Volcker Rule in the US and the "ring-fencing" of core retail banking from investment banking in the UK suggest that policymakers may be adopting this approach. 
A third principle guiding the design of the regulatory framework should be to reduce complexity in relation both to regulation and to the structures of regulated firms. The policy

implication of this principle is that regulation may be required to control the size and scope of banks - an argument which has been articulated convincingly by Johnson and Kwak (2011, p. 215).

\section{Regulation and individual behaviour}

Regulators seek the highest possible levels of compliance with regulation so the question of what motivates compliance with regulation - what drives compliant behaviour is therefore a fundamental one. Among other things, regulators' responses to this question inform the design of regulatory systems, particularly enforcement functions. Their answer is influenced - perhaps too heavily - by the assumption that human behaviour is largely a response to the risks and incentives in the environment. In a different and broader context the context of criminal justice - Tyler $(2009$, p. 308) points out that this assumption informs the dominant approach currently to obtaining compliance with the law which he describes as one of deterrence or "social control." Law-breaking is deterred though the fear of punishment. Individuals judge the risk attached to rule-breaking based on whether they are likely to be caught and the severity of the potential punishment. In a regulatory context, regulators have to "create and maintain a credible threat of punishment for wrongdoing" (2009, p. 309). Indeed, a UK regulator the FCA asserts that "credible deterrence is central to our enforcement work'[14].

At several points in this article the role of incentives in ensuring compliance with regulation has been assumed (see principles two, five and six, for example). This reflects the pre-eminence of an incentives-based view of the regulatory process in which non-compliance punished. (Compliance is rarely - if ever - rewarded, however.) The prominent role of 
incentives in regulation may reflect a broader trend for the growing use of incentives in many aspects of everyday life (Sandel, 2012, p. 43-91). That notwithstanding, it should be borne in mind that the "calculative / incentive-driven individual" is only one of several models of compliance motivation (Feldman 2011, pp. 335-46). Individuals might comply with regulation for reasons other than that they have been incentivized to do so. They may be motivated to comply because the regulations emanate from a legitimate authority, for example.

MacNeil and O'Brien (2010, p. 3) suggest that the fundamental issue to be addressed in the wake of the global financial crisis may be much broader than badly-designed incentives arguing that "the unrelenting focus on the punishment of individual malefactors serves to obscure [a] much more fundamental problem. Corporate malfeasance and misfeasance on the scale witnessed cannot be readily explained by individual turpitude." Cairns (2014, p. 239) emphasises the importance of changing the organizational culture of financial institutions through corporate governance reform as an appropriate response to the crisis. A response which focuses solely on regulatory reform will be "insufficient to change the culture within the financial system.” As Schein (2010, Exhibit 2.1) has observed, consideration of organizational culture introduces the dimension of values because culture and values are intertwined. At the deepest level of an organizational culture, the culture consists of the organizations "unconscious, taken-for-granted beliefs and values." Organizational culture was the focus of a post-crisis report by Spicer et al. (2014, pp. 12-13) on retail banking which noted that:

There is a consensus that if we are to avoid a re-run of the financial crisis, it is vital to profoundly change the culture of banking. At the same time, there is a recognition that changing the culture of banking is difficult. A new culture can't just be regulated into being. Rather, culture change is something banks themselves must take responsibility 
for and be held accountable for. Broader change in the industry culture should be a matter of collective action.

This strong focus on culture signals an implicit recognition of the importance of attitudes and values, including social values, as drivers of behaviour. This is not to suggest that noncompliance with regulation by individuals should not be deterred or punished. Indeed, as Kane (2009, p. 317) argues, one of the four key duties of a supervisor is their duty of "prompt corrective action" meaning that they "should stand ready to discipline rule-breakers whenever a violation is observed"[15]. A focus on culture does, however, broaden regulators' understanding of what motivates human behaviour. Based on interviews with white-collar criminals, Soltes $(2016$, pp. 62-3, 314) makes the point that by relying upon the notion of "bad apples" we underestimate the "significant role played by context and the surrounding culture." The correct way to frame our question, Soltes argues, is in terms of why people make bad decisions, rather than on innate characteristics. These bad decisions come about because we over-rely on "faulty intuition", we under-utilise "deliberative reasoning" and we have insufficient "exposure to differing viewpoints."

As Crane and Matten (2010, pp. 148-76) have noted in the context of ethical decisionmaking, decisions are affected by a range of individual factors and situational factors. While situational factors include rewards, they also include organisational culture. Individual factors include personal values, personal integrity and our capacity for "moral imagination." Tyler and Darley $(2000$, p. 715,708$)$ posit an alternative to the deterrence theory of compliance which they refer to as a "value-based perspective" which focuses on influencing social values to achieve compliance. Effective regulation must reinforce and strengthen support for values such as stability in banking, high professional standards in banking, and compliance with bank regulation [16]. 


\section{Banking as a practice}

A sixth guiding principle of regulation should be to develop banking as a 'practice', in the sense used in virtue ethics. MacIntyre (2007, p. 187) defines a practice as: "any coherent and complex form of socially established co-operative human activity through which goods internal to that form of activity are realized in the course of trying to achieve those standards of excellence which are appropriate to, and partially definitive of, that form of activity" [17]. Goods internal to the activity of banking are "goods of excellence." They derive from the exercise of the virtues. An internal good in the context of banking might be 'trustworthiness', generated through the exercise of virtues such as honesty, reliability and competence. Internal goods are contrasted with external goods, or "goods of effectiveness." These external goods are those things which are always some individual's property and possession and might include profits, dividends, share price, money, status, power, fame or prestige (2007, p. 188, 190). The pursuit of external goods, if taken to the extreme, can corrupt the practice of banking. More broadly, if society focuses solely upon the pursuit of external goods, argues MacIntyre (2007, p. 196) competitiveness will be the dominant or even exclusive feature of that society, as a result of which the virtues may decline or disappear: "We should therefore expect that, if in a particular society the pursuit of external goods were to become dominant, the concept of the virtues might suffer first attrition and then perhaps something near total effacement, although simulacra might abound."

The regulatory system should persuade or incentivize the pursuit of internal goods within the practice of banking. This is important for two reasons. First, a focus on banking as a practice will act as a counterweight to the underlying corporate governance assumption of shareholder primacy, with its pursuit of "goods of effectiveness." Second, such a focus would complement moves to professionalize banking in the aftermath of the global financial crisis 
[18]. The 2013 report "Changing Banking for Good" observed that, although a professional qualification had never been a formal requirement for being a banker, there has been a steep decline in membership of the professional body for banks, the Chartered Institute of Bankers, in recent decades:

In the $1980 \mathrm{~s}$, there were as many as 150,000 members of what was then the Chartered Institute of Bankers (CIB), and approximately 10,000 members of the Chartered Institute of Bankers in Scotland (CIOBS). CIB membership had fallen to no more than 22,000 by 2010 , with CIOBS/Institute membership remaining relatively constant at 10,500 . It is clear, however, that of the approximately 450,000 individuals employed in UK banking today, only a small proportion are professionally qualified in banking and members of a recognized professional body for bankers. In particular, only a small proportion of senior bankers are members of a recognized professional body for bankers [19].

It is worth noting in this context how banks' views as to what makes a suitable bank employee have changed, a process which began in the early 1970s. In 1971 the Midland Bank engaged McKinsey and Company, Inc. to carry out a review of its activities. Among other things, McKinsey's report recommended that there should be a change in the underlying philosophy for evaluating the performance of bank employees. Its recommendation had a highly contemporary ring: "we recommend that the bank should change its performance assessment from one based on personality traits to one based on achievement of results"[20].

The policy implication of this principle is that bank regulatory policies must encourage and / or incentivize the pursuit of professional excellence in banking at both the individual and the organisational level. Once the UK leaves the EU it would be a serious error to engage in a bank regulatory 'race to the bottom'. On the contrary, regulatory policy must support the highest possible standards of banking in the world. 


\section{Objectives of regulation and competition}

Bank regulation and competition policy should work in an integrated way towards four objectives, each of which advances the public interest. They have two social objectives. The first is to support the stability of the banking system by minimising the risk of systemic banking crises. Stability is a guiding objective of bank and financial system regulation because financial and banking crises can have severe social and economic consequences. Moreover, banking crises have become more prevalent since the 1970s. As for their costs and consequences, the cost of the global financial crisis to the US economy over the period 2008 to 2023 has been "conservatively" estimated by Atkinson et al. (July 2013, p. 2) to be between $\$ 6$ trillion and \$14 trillion in 2012 dollars. According to Eurostat, approved state aid measures in the EU between October 2008 and October 2010 in response to the crisis amounted to $€ 4.6$ trillion, while in 2009 alone the GDP of the EU contracted by 6 per cent due to the crisis-induced recession [21]. A second social objective of bank regulation and competition policy is to ensure the highest possible standards of banking and its development as a 'practice', as discussed under principle six. This particular objective is directed towards the protection of consumers of bank products and services, a sector in which there is often great asymmetry of information between provider and consumer, to the provider's benefit. This asymmetry has sometimes been exploited, as evidenced in the UK with the sale of Payment Protection Insurance. These first two objectives can be considered social objectives, defining that term broadly, because a stable banking system in which very high standards prevail has major implications for people's sense of security and stability.

Regulation and competition policy have a political purpose and the third policy objective is a political one, although it is rarely if ever framed as such. A banking industry with a few large banks may optimize productive efficiency in the industry because those 
banks may take advantage of economies of scale and scope. However, those few large banks may be or become 'Too Big to Fail', thereby undermining the political objective of dispersing power. This purpose of this objective is to prevent the development of a concentration of power, by controlling the power of private economic interests. It seeks to reduce the risk of the emergence of 'Too Big to Fail' banks and is also works as a defence against the process of regulatory capture [22]. As Novak (2014, p. 43) observes, regulation is a response to the ageold political problem of "business corrupting the body politic." Finally, regulation and competition have a fourth objective, the economic objective of ensuring productive and allocative efficiency in the industry.

Competition and regulation and the institutional framework within which banks operate all impose constraints. Each may play a role in advancing the social, political and economic objectives of bank regulation. Ideally the policy goals of competition and regulation will be both consistent and complementary, and also consistent with the wider institutional framework. They may, however, be in tension. This tension was acknowledged in the postwar period and was one reason for the authorities' reluctance to dismantle the clearing banking cartel which, although it moderated competition, was seen as a stabilizing phenomenon. A tension is evident in that the primary goal of competition policy may be to maximize the productive efficiency of the banking sector whereas regulatory policy may have the social goal of ensuring stability in banking. Competition policy focusing on efficiency may lean towards lower barriers to entry into banking while regulatory policy may favour higher ones, possibly at the expense of efficiency. The political goal of preventing monopoly may conflict with the competition objective of productive efficiency given that a banking industry with a few large banks may be able to take advantage of economies of scale and scope. On the other hand, those few large banks may be or become 'Too Big to Fail', thereby undermining the political objective of dispersing power. How should these tensions or 
conflicts be resolved? In regulatory policymaking the default position should be that the social and political objective(s) of bank regulation should prevail over the economic objective of allocative efficiency. If objectives other than efficiency are to be prioritised, however, this is likely have cost implications which may well increase the price of banking and financial services to consumers.

\section{Conclusion}

The primary purpose of this article is to set out seven guiding principles for effective bank regulation, drawing on research into the nature of bank regulation in the twenty-five to thirty years after the Second World War, so that they may be subject to academic criticism. They are as follows:

1. The basis of effective regulation is the legitimacy of the regulator(s) and of the regulations;

2. An effective regulatory framework depends upon the placing and accepting of trust. This in turn depends upon trustworthy banks and bank regulator(s);

3. There are limits to the effectiveness of codified, formal regulation;

4. The regulatory framework should promote simplicity and discourage complexity with respect to regulation and to the structure of regulated entities;

5. The regulatory framework should have a broad rather than a narrow conception of what drives individual behaviour within the regulatory process;

6. Regulation should encourage the development of excellence in banking, that is to say, the development of banking as a "practice";

7. The political and social objectives of regulation and competition must prevail over economic ones, if there is a conflict. 


\section{References}

Atkinson, T., Luttrell, D. and Rosenblum, H. (2013), "How Bad Was It? The Costs and Consequences of the 2007-09 Financial Crisis”, Staff Papers No. 20, Federal Reserve Bank of Dallas, available at: https://www.dallasfed.org/ /media/documents/research/staff/staff1301.pdf (accessed 11 June 2019).

Beadle, R. (2002), “The Misappropriation of MacIntyre”, Reason in Practice, Vol. 2 No. 2, pp. 45-54.

Beck, T., Carletti, E. and Goldstein, I. (2016), "Financial Regulation in Europe: Foundations and Challenges”, Discussion Paper 11147, Centre for Economic Policy Research.

Boddy, C. (2011), "The Corporate Psychopaths Theory of the Global Financial Crisis", Journal of Business Ethics, Vol. 102 No. 2, pp. 255-259.

Boulding, K. (1969), “The Legitimacy of Central Banks”, Steering Committee for the Fundamental Reappraisal of the Discount Mechanism Appointed by the Board of Governors of the Federal Reserve System.

Cairns, S. (2014), "Changing the Culture of Financial Regulation: A Corporate Governance Approach", PhD, University of Liverpool, available at: https://ethos.bl.uk/Home.do (accessed 11 June 2019).

Casu, B., Girardone C. and Molyneux P. (2015), Introduction to Banking, Pearson Education Limited, Harlow.

Coid, J., Yang, M., Ulrich, S., Roberts, A. and Hare, R. (2009), "Prevalence and Correlates of Psychopathic Traits in the Household Population of Great Britain", International Journal of Law and Psychiatry, Vol. 32 No. 2, pp. 65-73.

De Jonghe, O. (2010), "Back to the Basics in Banking? A Micro-analysis of Banking System Stability", Journal of Financial Intermediation, Vol. 19, pp. 387-417.

Dutton, K. (2013), The Wisdom of Psychopaths: Lessons in Life from Saints, Spies and Serial Killers, Arrow Books, London. 
Eastburn, D. (1970), “The Federal Reserve as a Living Institution: A Prescription for the Future”, in Eastburn, D.P. (Ed.), Men, Money \& Policy: Essays in Honor of Karl R. Bopp, Federal Reserve Bank of Philadelphia, pp. 253-66.

Feldman, Y (2011), "Five Models of Regulatory Compliance Motivation: Empirical Findings and Normative Implications”, Levi-Faur, D. (Ed.), Handbook on the Politics of Regulation, Edward Elgar Publishing Ltd., Cheltenham, pp. 335-46.

Finn, R. and Less, S. (2013), “Letters \& Notes on Regulation, No 2.2: Capture of Independent Sectoral Regulators”, Regulatory Policy Institute, Oxford.

Grossman, R. (2016), “Banking Crises”, Wesleyan Economic Working Papers No. 2016-001, Department of Economics, Wesleyan University, Middletown, CT.

Herring, R. and Carmassi, J. (2015), “Complexity and Systemic Risk: What's Changed since the Crisis?", in Berger, A.N., Molyneux, P. and Wilson, J.O.S. (Eds.), The Oxford Handbook of Banking: Part 1: The Theory of Banking, Oxford Handbooks Online, Oxford University Press, Oxford.

Johnson, S., Kwak, J. (2011), 13 Bankers: The Wall Street Takeover and the Next Financial Meltdown, Vintage Books, New York, NY.

Jones, B. (1999), "Bounded Rationality”, Annual Review of Political Science, Vol. 2, pp. 297-321.

Kane, E. (2009), "Regulation and Supervision: An Ethical Perspective”, in Berger, A.N. and Molyneux, P. (Eds.), Oxford Handbook of Banking, Oxford University Press, Oxford, pp. 315338.

Laeven, L. and Valencia, F. (2012), "Systemic Banking Crises Database: An Update", Working Paper 12/163, International Monetary Fund

MacIntyre, A. (2007), After Virtue, University of Notre Dame Press, Notre Dame, IN.

MacNeil, I. and O’Brien, J. (2010), “Introduction: The Future of Financial Regulation”, in MacNeil, I. O’Brien, J. (Eds.), The Future of Financial Regulation, Hart Publishing, Oxford, pp. 1-22. Marandola, G. and Sinclair, T. (2014), “Credit Rating Agencies: A Constitutive and Diachronic Analysis", SPERI Paper No. 16, Sheffield Political Economy Research Institute, The University of Sheffield, Sheffield. 
Mayer, R., Davis, J. and Schoorman, F. (1995), “An Integrative Model of Organizational Trust”, The Academy of Management Review, Vol. 20 No. 3, pp. 709-734.

McBarnet, D. (2010), "Legal Work, Legal Integrity and the Banking Crisis" in MacNeil I. and O’Brien J. (Eds.), The Future of Financial Regulation, Hart Publishing, Oxford, pp. 67-82.

Nooteboom, B. (2014), How Markets Work and Fail and What to Make of Them, Edward Elgar, Cheltenham.

Novak, W. (2014). “A Revisionist History of Regulatory Capture”, in Carpenter D. and Moss D.A. (Eds.), Preventing Regulatory Capture: Special Interest Influence and How to Limit It, Cambridge University Press, New York, NY, pp. 25-48.

O’Neill, O. (2014), “Building Trust”, a lecture, Saïd Business School, University of Oxford, 20 November 2014.

Reinhart, C., Rogoff, K. (2009), This Time Is Different: Eight Centuries of Financial Folly, Princeton University Press, Princeton, NJ.

Sandel, M. (2012), What Money Can't Buy: The Moral Limits of Markets, Penguin Group, London.

Schein, E. (2010), Organizational Culture and Leadership, Jossey-Bass, A Wiley Imprint, San Fransisco, CA.

Searle, J. R. (2005), “What Is an Institution?”, Journal of Institutional Economics Vol 1, no. 1, pp. 122.

Slattery, D. and Nellis J. (2011), "Rethinking the Role of Regulation in the Aftermath of the Global Financial Crisis: The Case of the UK", Panoeconomicus, Vol. 58 No. 3, pp. 407-423.

Soltes, E. (2016), Why They Do It: Inside the Mind of the White Collar Criminal, Public Affairs, New York, NY.

Spicer, A., Gond, J., Patel, K., Lindley, D., Fleming, P., Mosonyi, S., Benoit, C. and Parker, S. (2014), "A Report on the Culture of British Retail Banking", New City Agenda and Cass Business School, City University London.

Taylor, A. (2010), “Global Finance After the Crisis”, Bank of England Quarterly Bulletin, Q4 2010, pp. 366-377. 
Tosh, J. (1992), The Pursuit of History: Aims, Methods and New Directions in the Study of History, Longman Group UK Limited, London.

Tyler, T. (2009), “Legitimacy and Criminal Justice: The Benefits of Self-Regulation”, Ohio State Journal of Criminal Law, Vol. 7, pp. 307-359.

Tyler, T. and Darley J. (2000), "Building a Law-Abiding Society: Taking Public Views about Morality and the Legitimacy of Legal Authorities into Account When Formulating Substantive Law", Hofstra Law Review Vo. 28, pp. 707-739.

Umpleby, S. (1989), "Strategies for Regulating the Global Economy”, Futures, Vol. 21 No. 6, pp. 585592.

Watson, M. (2013), “Policy Brief: From Regulatory Capture to Regulatory Space?”, The Foundation for Law, Justice and Society, Oxford, pp. 1-8.

Wolf, M. (2004), Why Globalisation Works, Yale University Press, London.

\section{Endnotes}

1 “Basel III: A Global Regulatory Framework for More Resilient Banks and Banking Systems," December 2010, revised June 2011, The Basel Committee on Banking Supervision, Bank for International Settlements, accessed 11 June 2019, http://www.bis.org/publ/bcbs189.pdf.

2 “Changing Banking for Good: Report of the Parliamentary Commission on Banking Standards, Volume II,” paras. 980-2, www.parliament.uk, accessed 11 June 2019, http://www.parliament.uk/documents/banking-commission/Banking-final-report-vol-ii.pdf. ${ }^{3}$ Lord Turner of Ecchinswell (Adair Turner) was chair of the Financial Services Authority from 2008 until 2013. Martin Wheatley was chief executive of the Financial Conduct Authority from 2013 until 2015.

${ }^{4}$ In addition to the two sources mentioned in the text, Boulding identifies age, mystery, ritual, and alliances with other legitimate institutions as the other sources of legitimacy. 
${ }^{5}$ Leslie Kenneth O’Brien interviewed by Kay Sanderson, Tape Two, National Life Stories Collection: City Lives, British Library: C409/003.

6 “British Social Attitudes 302013 Edition,” accessed 18 June 2019, http://www.bsa.natcen.ac.uk/media/38723/bsa30_full_report_final.pdf, pp. xv-xvi.

7 “A Question of Confidence," Men and Money, edited by Alan Martin, broadcast on 28 April 1964 on BBC Two. BBC Archive, accessed 11 June 2019, http://www.bbc.co.uk/archive/menandmoney/6801.shtml.

8 “What We Don't Understand About Trust," TED: Ideas Worth Spreading, accessed 11 June 2019 https://www.ted.com/talks/onora_o_neill_what_we_don_t_understand_about_trust/transcript? language $=\mathrm{en}$.

9 “What We Do,” Office for Budget Responsibility, accessed 11 June 2019, http://budgetresponsibility.org.uk/about-the-obr/what-we-do/. 10 "What We Don't Understand About Trust," TED: Ideas Worth Spreading, accessed 11 June 2019, https://www.ted.com/talks/onora_o_neill_what_we_don_t_understand_about_trust/transcript? language $=\mathrm{en}$.

${ }^{11}$ This is not exclusively the case. There are examples of principles-based, rather than rulesbased, approaches to bank supervision and regulation prevailing since the global financial crisis. For example, the Basel Committee on Banking Supervision reviewed and re-issued its "Core Principles [my emphasis] for Effective Banking Supervision" in September 2012. See “Core Principles for Effective Banking Supervision,” Bank for International Settlements, accessed 11 June 2019, https://www.bis.org/publ/bcbs230.htm. 
12 "Basel III: The Liquidity Coverage Ratio and Liquidity Risk Monitoring Tools, January 2013," Basel Committee on Banking Supervision, accessed 11 June 2019, https://www.bis.org/publ/bcbs238.pdf, Introduction.

${ }^{13}$ Bounded rationality is a theory of decision-making which "assumes that actors are goaloriented, but [...] takes into account the cognitive limitations of decision makers in attempting to achieve these goals." This leads to "satisficing" rather than optimizing behaviour. Bounded rationality would apply to those regulating as well as those being regulated. See Jones (1999).

14 “Enforcement," Financial Conduct Authority, accessed 11 June 2019, https://www.fca.org.uk/about/enforcement.

15 The other key duties are: a duty of vision, a duty of efficient operation and a duty of conscientious representation.

${ }^{16}$ The president of the Federal Reserve Bank of Philadelphia from 1970 to 1981 David P. Eastburn (1970) argued that, "The Fed must try to influence society's choice of values as well as adapt to them."

${ }^{17}$ The idea that corporations can be practice-based communities is contested. See, for example, Beadle (2002).

${ }^{18}$ This issue was discussed in "Changing Banking for Good: Report of the Parliamentary Commission on Banking Standards, Volume II,” paras. 567-611,www.parliament.uk, accessed 11 June 2019, http://www.publications.parliament.uk/pa/jt201314/jtselect/jtpcbs/27/27ii08.htm\#a117. 19 “Changing Banking for Good: Report of the Parliamentary Commission on Banking Standards, Volume II,” paras. 571-2, www.parliament.uk, accessed 11 June 2019, http://www.publications.parliament.uk/pa/jt201314/jtselect/jtpcbs/27/27ii08.htm\#a117. 
${ }^{20}$ McKinsey \& Company Inc., "Strengthening Midland's Ability to Grow Profitably,” vii, 1 February 1971, HSBC Group Archives: Records of Chairman (Forbes, Archibald), McKinsey, UK 0346-0003.

21 “Capital Requirements - CRD IV/CRR - Frequently Asked Questions," European Commission, accessed 10 October 2018, http://europa.eu/rapid/press-release_MEMO-13690 en.htm.

${ }^{22}$ Finn \& Less (2013) define regulatory capture as "the tendency for regulators to take decisions that are biased in favour of the interests of the industry they regulate rather than the customers or wider society on whose behalf they regulate." 